\title{
Title: Mapping urban forest structure and function using hyperspectral imagery and lidar data
}

\section{Authors:}

Michael Alonzo ${ }^{1 *}$, Joseph P. McFadden ${ }^{2}$, David J. Nowak ${ }^{3}$, Dar A. Roberts ${ }^{2}$

1 NASA Goddard Space Flight Center, Greenbelt, MD 20771

2 Department of Geography, University of California Santa Barbara, CA 93106

3 USDA Forest Service, Northern Research Station, 5 Moon Library, SUNY-ESF, Syracuse, NY 13210

* Corresponding author

Email: mike.alonzo@geog.ucsb.edu

Phone: +01-805-883-8821

Present and permanent address for corresponding author as noted above 


\section{Abstract}

2 Cities measure the structure and function of their urban forest resource to optimize forest management

3 and the provision of ecosystem services. Measurements made using plot sampling methods yield useful

4 results including citywide or land-use level estimates of species counts, leaf area, biomass, and air

5 pollution reduction. However, these quantities are statistical estimates made over large areas and thus

6 are not spatially explicit. Maps of forest structure and function at the individual tree crown scale can

7 enhance management decision-making and improve understanding of the spatial distribution of 8 ecosystem services relative to humans and infrastructure. In this research we used hyperspectral 9 imagery and waveform lidar data to directly map urban forest species, leaf area index (LAI), and carbon 10 storage in downtown Santa Barbara, California. We compared these results to estimates produced using 11 field-plot sampling and the i-Tree Eco model. Remote sensing methods generally reduced uncertainty in 12 species-level canopy cover estimates compared to field-plot methods. This was due to high classification 13 accuracy for species with large canopies (e.g., Platanus racemosa with 90\% average accuracy, Pinus 14 pinea at $\sim 93 \%$, Quercus agrifolia at 83\%) and high standard error of the plot-based estimates due to 15 the uneven distribution of canopy throughout the city. Average LAI in canopy, based on lidar 16 measurements was 4.47 while field measurements and allometry resulted in an LAl of 5.57. Citywide 17 carbon storage, based on lidar measurements and allometry was estimated at 50,991 metric tons ( $t$ ) and $55,900 \mathrm{t}$ from plot-sampling. As others have noted, carbon density varied substantially by development intensity based largely on differences in fractional cover but less so when only evaluating canopy

20 biomass. Using separate biomass equations for each leaf type (broadleaf, needleleaf, palm) resulted in a more accurate carbon map but a less accurate citywide estimate. 


\section{Introduction}

Measurement of urban forest structure is a prerequisite to estimating urban forest ecological functions such as urban heat island mitigation, air pollution removal, carbon storage, building energyuse modification, and stormwater runoff reduction. Measurements of structure are generally based on a limited set of random field plots given the impracticality of a complete urban tree inventory (Nowak et al., 2008a). Estimates of urban forest function are commonly made using the USDA Forest Service's iTree Eco (formerly Urban Forest Effects or UFORE) model (www.itreetools.org; Nowak et al., 2008a). Many cities use the model outputs to improve urban forest management and inform environmental policy (e.g., McPherson et al., 2011). However, field sampling methods come with potential drawbacks: (1) they are labor and time intensive, generally taking a trained, 2-person field crew 14 weeks to sample 200 0.04-ha plots (Nowak et al., 2008b); (2) they can be expensive, depending upon local transportation and labor costs (3) permission to access plots may be limited in some areas; (4) the magnitudes of fundamental outputs such as species and tree size distributions are subject to sampling error that are dependent upon sample size and forest structural variability; (5) the results are averages or totals within land-use classes and not spatially explicit across the city.

Generation of spatially explicit outputs is important for several reasons: First, it is critical for urban forest managers to know the specific locations of common species so they can prepare for threats from pests, fire, and blight (Laćan \& McBride, 2008; Santamour, 1990; White \& Zipperer, 2010). Second, the magnitudes of ecosystem functions vary spatially throughout the city based largely on canopy leaf area index (LAI) and tree spatial context. LAl distribution and context in turn depend on historical tree planting patterns (e.g., allées, stock availability, neighborhood age), natural regeneration, tree site suitability, water availability, infrastructure conflicts, maintenance, street traffic, etc. (Escobedo \& Nowak, 2009; Manning, 2008; McCarthy \& Pataki, 2010; McPherson et al., 2011; Nowak, 2012; Simpson, 2002; Urban, 1992). Third, ecosystem services may not be distributed fairly with respect to class and race: Communities that would benefit the most from improved air quality, cooler temperature and even reduced crime (Kuo \& Sullivan, 2001) are frequently those with the least access to canopy (Heynen et al., 2006; Schwarz et al., 2015). Fourth, with respect to carbon storage: there is only limited work pertaining to the global carbon cycling implications of urban expansion (Churkina et al., 2010; Hutyra et al., 2011). Spatially explicit accounting for variation in carbon storage will better constrain cities' roles as C sinks and improve understanding of ecosystem response to urbanization.

In contrast to extensive field sampling, remote sensing can provide spatially extensive data, potentially with higher temporal resolution and lower cost. However, the use of remote sensing in the 
development of urban forest inventories has been limited due to the spatial and spectral complexity of urban landscapes (Herold et al., 2004). For example, Landsat, a space-borne, multispectral sensor is not well suited to this problem because of its $30 \mathrm{~m}$ ground instantaneous field of view, which is much larger than the characteristic scale of spatial variation found in urban areas ( $\sim-10 \mathrm{~m}$; Jensen \& Cowen, 1999; Welch, 1982; Woodcock \& Strahler, 1987). High spatial resolution $(<3 \mathrm{~m})$, multispectral platforms such as IKONOS and GeoEye as well as aerial imagery have allowed for precise mapping of urban forest canopy extents (MacFaden et al., 2012; Richardson \& Moskal, 2014) but limited spectral information largely precludes species identification or structural quantification. However, successful discrimination of urban forest tree species has been shown possible using either only hyperspectral imagery (Alonzo et al., 2013; Xiao et al., 2004) or hyperspectral imagery fused with light detection and ranging (lidar) data (Alonzo et al., 2014; Zhang \& Qiu, 2012). Leaf area index (LAI) has also been accurately estimated at fine spatial scales using both lidar penetration ratios as a proxy for gap fraction and allometric estimates based on individual crown structural measurements (Alonzo et al., 2015).

While the ability to map urban forest structure at high spatial resolution has been demonstrated, citywide maps of structure and attendant functions have not yet been produced. The primary goal of this paper is to examine the capability of hyperspectral imagery and lidar data to produce citywide maps of key structural attributes: tree species, LAI, and carbon storage. Our secondary goal is to evaluate the statistical uncertainty of the maps and to assess how they may be used with other types of spatial data to address urban ecological questions. The specific objectives of this paper are as follows:

1. Scale the species identification methods developed by Alonzo et al. (2014) and the LAl estimation methods from Alonzo et al. (2015) into citywide maps.

2. Create a citywide map, at the individual tree crown scale, of dry-weight carbon storage using lidar crown measurements and allometric scaling.

3. Analyze the spatial patterns of each map to demonstrate the utility of spatially explicit representation and to characterize the uncertainties of the remote sensing methods.

4. Compare the remote sensing outputs with i-Tree Eco outputs generated using traditional plot-sampling methods 


\section{Methods}

\subsection{Study site description}

This study was conducted in downtown Santa Barbara, California $\left(22 \mathrm{~km}^{2} ; 34.42^{\circ} \mathrm{N}, 119.69^{\circ} \mathrm{W}\right)$

(Fig 1). Santa Barbara is a city of about 90,000 residents located on a coastal plain between the Pacific Ocean to the south and the Santa Ynez mountains to the north. It has a Mediterranean climate and supports a diverse mix of native, introduced, and invasive urban forest species. The study area represents $45 \%$ of the total area of the city. We chose the specific boundaries in order to focus on the most characteristically urban parts of the city and based on availability of contemporaneous lidar and hyperspectral data. The city of Santa Barbara maintains a spatial database that contains one or more specimens from $>450$ tree species. While collecting i-Tree inputs at 105 plots, 108 unique species were recorded. Despite this diversity, based on i-Tree and municipal data, we estimated that only 25 species represent approximately $80 \%$ of the city's canopy cover. The most common and canopy dominant native species is Quercus agrifolia (Coast live oak). The most common introduced species in terms of stem count is the Syagrus romanzoffiana (Queen palm).

\subsection{Field data collection and the i-Tree Eco model}

In the fall of 2012 we took measurements at 105, $11.4 \mathrm{~m}$ radius field plots that were randomly distributed in 105 grid cells subdividing the study area. In this study, we screened out 16 of the northernmost plots because they fell within the boundaries of a hyperspectral flight line that was unusable due to errors in reflectance retrieval. Thus, 89 plots were retained for further analysis. At the time of data collection we were unable to gain permission to take measurements at 9 private property plots. For each access denial, a new plot location was randomly generated in the same grid square. Plots were not stratified by land use in this study but nonetheless were distributed roughly in proportion to the major land use classes provided by the City of Santa Barbara (Table 1). The land use classes chosen for this study are common urban classes that are similar to those defined in other i-Tree Eco studies such as Los Angeles (Nowak et al., 2010) and Washington, DC (Nowak et al., 2006). The aggregated class, Natural-Agricultural-Recreation includes open, undeveloped lands and some parks which house most of the area's native stands of Quercus and Platanus.

At each plot, we identified and measured all trees with diameter at breast height $(\mathrm{dbh})>2.5 \mathrm{~cm}$

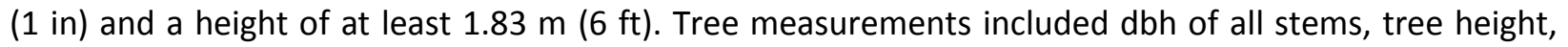
height-to-live-top, crown diameter (North - South), crown diameter (East - West), crown base height, 
121

122

123

124

125

126

127

128

129

130

131

132

133

134

135

136

137

138

139

140

141

142

143

crown missing, and dieback. We also measured the distance and direction of each tree from each

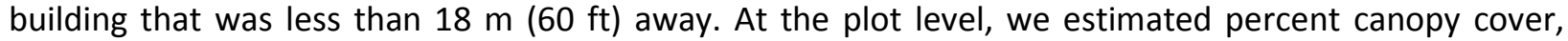
ground cover class percentages, and land-use class percentages (i-Tree Eco User's Manual v. 4.1.0, www.itreetools.org). At each plot in which one or more trees were present, we took up to 5 near infrared, hemispherical photographs to measure plot-level gap fraction and LAI (Alonzo et al., 2015).

We used the i-Tree Eco software application to generate a statistically based estimate of urban forest structure and function. In i-Tree, primary estimates of structure include stem counts by species, size class distributions, and LAI. While species and size class distributions are directly estimated from field sampling, LAI is allometrically estimated using an equation developed for open-grown trees (Nowak, 1996). Ecosystem functions such as air pollution reduction, carbon storage, building energy modification, and stormwater runoff reduction are estimated from tree measurements and ancillary, contextual variables. Reduction of airborne $\mathrm{CO}, \mathrm{O}_{3}, \mathrm{NO}_{2}, \mathrm{SO}_{2}$, and $\mathrm{PM}_{2.5}$ is modeled as a function of tree LAI, hourly meteorological data, and local hourly pollution concentrations. The economic value of the associated human health benefit additionally requires population density information (Nowak et al., 2014). Fresh weight carbon is estimated using measurements of dbh and height input into species, genus, or leaf-type specific equations from the literature (McHale et al., 2009; Nowak \& Crane, 2002). Fresh weight is converted to total dry-weight carbon using literature values (Nowak \& Crane, 2002). Trees modify building energy use through direct shading, evapotranspiration, and windbreak effects. These building energy benefits and avoided carbon emissions from associated power production are estimated from tree size, distance and direction to buildings, climate region, leaf type, canopy cover, regional energy production information, and building construction information (McPherson \& Simpson, 1999b). Stormwater runoff reduction can be estimated from canopy cover, LAI, land cover, and local weather data (Wang et al., 2008).

The i-Tree Eco model is subject to the following uncertainties: 1) measurement error in the field data collection, which is generally assumed to zero; 2 ) sampling error that can be characterized by the standard error of the estimate; and 3) model error (e.g., error in applying allometric equations, conversion factors, pollution removal models) that is generally of unknown magnitude (Nowak et al., 2008a), but is demonstrably low enough to produce reasonable estimates compared with field measurements (Morani et al., 2014; Peper \& McPherson, 2003) or other standardized field/model estimates (Nowak et al., 2013a). 


\subsection{Remote sensing data and processing}

Full waveform lidar data were collected in August of 2010 with a helicopter-mounted Riegl Q560 scanner. The waveform was discretized to an average, last-return pulse density of $22 \mathrm{pts}^{-2}$ with additional returns available in tree canopy. The lidar returns were classified as ground, building, or tree canopy using LASTools (LAStools v111216, http://lastools.org) with minimal adjustments to default settings. Finally, a gridded $(0.25 \mathrm{~m})$ canopy height model was exported for use in crown segmentation algorithms.

Hyperspectral imagery was collected using the Airborne Visible/Infrared Imaging Spectrometer (AVIRIS; Green et al., 1998). The two radiance images used in this study were acquired on November 1, 2010 at approximately 11:50 and 14:20 Pacific Standard Time (PST). AVIRIS is a 224 channel system that samples radiance at $10 \mathrm{~nm}$ intervals across the solar-reflected spectrum from $365 \mathrm{~nm}$ to $2500 \mathrm{~nm}$. This spectral range and resolution allows for identification of leaf pigment absorption features such as chlorophyll in the visible wavelengths of light (Ustin et al., 2009), characterization of leaf abundance and structure using the near infrared wavelengths (Roberts et al., 2004) and assessment of water status and lignin-cellulose features in the shortwave infrared (Kokaly et al., 2009). The radiance images were converted to surface reflectance using ATCOR-4 (Richter \& Schlaepfer, 2002) and 178 bands with adequate signal-to-noise ratios and minimal water vapor contamination were retained for analysis. The two AVIRIS images were mosaicked together at a final pixel resolution of $3.7 \mathrm{~m}$. The hyperspectral mosaic was co-registered to the lidar using Delaunay triangulation.

172 imagery must be segmented into crowns. Crown segmentation is frequently inaccurate particularly in

173 forests characterized by overlapping, broadleaf crowns (Ferraz et al., 2012). However, urban areas 174 contain many isolated trees that make automated segmentation more straightforward. The marker175 controlled watershed segmentation algorithm used in this study is described in detail in Alonzo et al. 176 (2014). In brief: Tree tops are isolated ("marked") on the gridded canopy height model and crowns are

177 "grown" from each tree top until a local minimum is reached. This minimum ideally corresponds with a 178 boundary where two or more crowns overlap. This method was $83 \%$ accurate in the Santa Barbara study 179 area with success defined as a watershed segment containing one-and-only-one tree stem. Areas of inaccuracy primarily corresponded to natural forest stands which were relatively homogeneous with 


\subsection{Species mapping}

It is currently not possible to distinguish all species in a species diverse urban forest using either field sampling or remote sensing methods. Thus, in this study we used cumulative canopy cover distributions calculated from i-Tree data and the city's public tree database to choose 29 common species that accounted for the greatest proportion of the canopy cover (Table 2, col A and C). We chose to quantify canopy cover instead of stem counts because there is a more direct relationship between canopy area and the magnitude of ecosystem function and it is a more straightforward quantity to measure from an airborne platform. Alonzo et al. (2014) developed a method for classifying the common species in the Santa Barbara study area using fusion of lidar measurements and hyperspectral data at the crown scale. In brief, this method fused the information from 178 AVIRIS bands with 7 lidarderived structural metrics (e.g., tree height, width-to-height ratios, crown porosity) for each segmented tree crown and classified that crown using canonical discriminant analysis (Fig 2). Crowns that were not one of the 29 common species were classified as one of the common species and their classification was deemed correct when leaf type (e.g., broadleaf, needleleaf, palm) agreement was achieved. For example, if a less common, persistent broadleaf, Quercus virginiana, was modeled as Quercus agrifolia or as Magnolia grandiflora, leaf type agreement was successful. In Alonzo et al. (2014) this method was tested on 2,304 crowns which represents approximately $1 \%$ of the total stems in the study area. In the current paper, we scale the method to map 290,000 stems (i-Tree estimate) or 179,043 segments generated from the canopy height model. This map allows for analysis of spatial patterns throughout the city and direct comparison to i-Tree estimates.

With the final map we offer additional analyses including: (1) error assessment based on comparison with the city of Santa Barbara's point dataset containing $>450$ species; (2) comparison of citywide canopy by species with i-Tree Eco estimates; (3) quantification of uncertainties in the remote sensing result due to segmentation and classification error and the uncertainties in the i-Tree Eco result stemming from sampling error of species and crown size distributions; and (4) analysis of how the classification algorithm mapped the uncommon species (i.e., whether leaf type agreement was achieved)

For canopy area, the i-Tree standard error of the estimate $\left(\sigma_{e}\right)$ can be calculated based on the mean and standard deviation of canopy area (per species) across the 89 plots. The more evenly spread a species' canopy area is among 89 plots, the lower the $\sigma_{\mathrm{e}}$. The error is driven by both the geographic distribution of a given species (presence/absence), and the sampling distribution of the species canopy area. It should be noted that in a standard i-Tree project, data are typically collected on 200+ plots 
which has yielded an average relative standard error in the stem count estimate of $12 \%$ (Nowak et al., 2008b). In this study, across 89 plots, for total stem count, $\sigma_{e}=19.3 \%$. Thus, we expect that errors reported from the field-plot analysis are higher than normal. The most directly comparable estimate of remote sensing uncertainty is quantity disagreement. This metric is formulated for each species as (mapped canopy - actual canopy)/actual canopy. Like the i-Tree estimates, it does not take into account location disagreement, which is instead conveyed by the Producer's (error of omission) and User (error of commission) accuracies (Table 2, cols F-H, Congalton, 1991).

\subsection{Leaf area index mapping}

Leaf area index can be defined as the one-sided total leaf area per unit ground area (Chen \& Black, 1992). It is an important ecophysiological quantity that, in urban areas, strongly mediates air pollution removal (e.g., Hirabayashi et al., 2011), dampening and delay of stormwater runoff (e.g., Xiao \& McPherson, 2002), and cooling through shading and evapotranspiration (e.g., Peters \& McFadden, 2010). In i-Tree, LAI is measured allometrically using a formula initially created for deciduous, opengrown trees (Nowak, 1996):

$$
\ln (\mathrm{LA})=-4.3309+0.2942 \mathrm{~L}+0.7312 \mathrm{D}+5.7217 \mathrm{~S}-0.0148 \mathrm{C}+\epsilon
$$

where $L A$ is leaf area, $L$ (crown length) is equal to the height of crown live top minus crown base height, $D$ is the average crown diameter, $S$ is a species-specific average shading factor, $C$ is the crown's outer surface area represented by: $\pi D(L+D) / 2$ and $\epsilon$ is an error term. LAl is computed for each sample tree by dividing $L A$ by the crown projection area.

This study followed the method developed in Alonzo et al. (2015) for estimating LAl at the crown scale allometrically. In brief: From each segment, tree height and crown base height were estimated from the lidar point cloud. Average crown diameter was calculated from watershed crown area after abstracting each segment to its circle of equivalent area. The derived input variables were calculated with high accuracy: Crown diameter root mean squared error (RMSE) $=0.77 \mathrm{~m}\left(\mathrm{r}^{2}=0.95\right)$, crown length RMSE $=1.72 \mathrm{~m}\left(\mathrm{r}^{2}=0.87\right)$, and crown surface area RMSE $=47.1 \mathrm{~m}^{2}\left(\mathrm{r}^{2}=0.94\right)$. In place of a speciesspecific shading factor, one scaling equation was developed for each leaf type using weighted linear regression on the log-transformed predictor and response variables. The final equations were as follows:

$$
\begin{aligned}
& \ln \left(\mathrm{LA}_{\mathrm{b}}\right)=\ln \left(1.76+0.60 \mathrm{~L}_{\mathrm{b}}+2.32 \mathrm{D}_{\mathrm{b}}-0.44 \mathrm{C}_{\mathrm{b}}\right) \\
& \ln \left(\mathrm{LA}_{\mathrm{n}}\right)=\ln \left(-5.05-2.06 \mathrm{~L}_{\mathrm{n}}-5.38 \mathrm{D}_{\mathrm{n}}+4.90 \mathrm{C}_{\mathrm{n}}\right) \\
& \ln \left(\mathrm{LA}_{\mathrm{p}}\right)=\ln \left(7.02+2.11 \mathrm{~L}_{\mathrm{p}}+11.09 \mathrm{D}_{\mathrm{p}}-5.33 \mathrm{C}_{\mathrm{p}}\right)
\end{aligned}
$$


where the subscripts $b, n$, and $p$ denote broadleaf, needleleaf, and palm leaf types respectively. When applied to the segments intersecting with i-Tree field plots and validated against plot-aggregated values, the plot-level equation was $y=0.10+0.97 x\left(\right.$ RMSE $=0.53, r^{2}=0.84$, where $x$ is the lidar estimate and $y$ is the field estimate) indicating good linear agreement.

In the present study, we (1) produce a citywide, crown-scale map of LAl; (2) sum total leaf area by distance and direction from single family homes as a first step to producing a citywide energy benefit map; (3) discuss errors and uncertainties of the remotely sensed map product compared to the i-Tree output.

\subsection{Carbon mapping}

Generally, inputs to allometric equations to predict carbon storage are either based on dbh alone, or dbh and tree height, and equations are species specific when possible or matched by genus or leaf type otherwise (Pillsbury et al., 1998). It is difficult to estimate dbh accurately from airborne remote sensing platforms (Popescu, 2007). Instead, we relied on the same set of 28 structural metrics (e.g., median height of lidar returns in crown, average lidar return intensity below median height) extracted from each crown segment by Alonzo et al. (2014). These metrics can be generally grouped as relating to tree height, tree width at various heights, crown porosity, vertical distribution of woody and foliar elements, and several derived ratio metrics. Using subsets of these structural measurements, we developed three equations, one for each leaf type, to directly predict dry-weight carbon storage. The general form of our scaling equation was:

$$
C=b_{0}(\operatorname{Var} 1)^{b_{1}}(\operatorname{Var} 2)^{b_{2}}
$$

267 where C is dry-weight carbon (used here synonymously with biomass) from field estimates, Var1 and Var2 are the best performing structural metrics and $b_{0,1,2}$ are empirically-determined coefficients. We also developed a single, pooled equation for the purpose of comparison. We hypothesized that the separate equations would predict biomass more accurately because they can more closely align with the

272 biomass clearly vary by leaf type. For example, height has been shown to predict biomass well in a 273 setting dominated by broadleaf trees (Raciti et al., 2014) but using only height to estimate palm tree biomass will likely lead to large overestimates. 
needleleaf, 26 palms). Two variables for each leaf type were selected. MAD was used instead of RMSE

278 because it deemphasizes outlier error and should lead to higher map accuracy albeit at the cost of

279

280

281

282

283

284

285

286

287

288

289

290

291

292

293

294

295

296

297

298

299

300

301

302

303

304

305

306 reducing the accuracy of the citywide estimate. For each leaf type and for the pooled model, the selected variables were used to determine coefficients for equation $\mathbf{5}$ and, following correction for logarithmic bias (Sprugel, 1983), applied to the entire study area where the leaf type information was available from the species classification result. The mapped result was validated by aggregating the crown level carbon estimates from lidar to the field-plot level and comparing with aggregated estimates from field measurements.

\section{Results and discussion}

\subsection{Tree species mapping}

A species map for the full study area was generated at crown scale and also, for visual clarity resampled to a $10 \mathrm{~m}$ grid (Fig 3). As previously reported in Alonzo et al. (2014) the sample overall accuracy of the map for the canopy area of the 29 common species is $83.4 \%$. The individual species accuracies ranged between $37 \%$ for the small, broadleaf Metrosideros excelsa, and $96 \%$ for the large broadleaved Eucalyptus globulus and Ficus microcarpa. This number is reported as the average of the Producer's and User accuracies which are broken out in Table $\mathbf{2}$ columns $\mathbf{G}$ and $\mathbf{H}$.

We conducted further error analysis on the citywide map (assessed against City of Santa Barbara street tree data) to confirm the stability of the sample results for the ten species with the most canopy area. It is not as straightforward to assess error for the full map because of the significant number of less common species that were mapped as one of the 29 common species. However, it is also interesting to note which uncommon species were most likely classified as one of the ten most common species (Table 3). This information helps to address questions about plant functional similarities that manifest both spectrally and structurally. The Producer's accuracies for the street tree sample were consistent with the sample accuracies from Alonzo et al. (2014). In lieu of User accuracies, we show here the percent of canopy mapped as a common species that is actually an uncommon species. For example, the uncommon species mapped more than any other as Eucalyptus globulus was Eucalyptus cornuta, and overall, $42 \%$ of street trees mapped as Eucalyptus globulus were actually uncommon species. Likewise, $20 \%$ of canopy mapped as Quercus agrifolia was actually an uncommon species, most frequently Quercus ilex. In all cases but one (Cupressus macrocarpa mapping Melaleuca quinquinervia) leaf type agreement was achieved. 
In certain cases, the degree to which a common species tended to be over-mapped relative to either other common species or uncommon species was flight-line dependent. Schinus terebinthifolius was much more frequently selected to map uncommon species, particularly Cupaniopsis anacardioides, in the southernmost flight line (Fig 3d). City tree planting data does indicate that more Schinus terebinthifolius were planted in this topographically distinct part of the city but spatial coincidence

312 between this species and the southern AVIRIS flight line is visually striking. This outcome can be 313 attributed to poor lighting geometry: the solar zenith angle for this flight line was $54^{\circ}$ which likely 314 resulted in signal attenuation, especially in a forward scattering sensor view configuration. That 315 Cupaniopsis anacardioides, in particular, was most frequently mapped as Schinus terebinthifolius, is not 316 surprising: They are quite similar in terms of crown structure, leaf size, and leaf color.

More often, species distributions were scattered throughout the city with locations more dependent on land use and ecological niches than remote sensing artifacts. In a natural setting, our map showed the interspersion of the common riparian species, Platanus racemosa among the Quercus agrifolia stands following a stream channel (Fig 3a). Our map also characterized the linear planting patterns along city streets well: Note the preferential planting of Magnolia grandiflora, Jacaranda mimosifolia, and Eucalyptus ficifolia in a single-family residential neighborhood (Fig 3b). Finally, on a citywide scale, one can see the locally-clumped yet globally distributed pattern of Eucalyptus globulus (Fig 3c). The clumps are likely naturally regenerating Eucalyptus stands frequently colocated with oak woodlands, while the linear patterns (most notably along Highway 101) likely represent intentional planting for aesthetic purposes and noise abatement.

\subsection{Comparing remote sensing and i-Tree species results}

Total canopy area for the 25 common species ${ }^{1}$ that were sampled by both remote sensing and i329 Tree was estimated as 5,584,589 $\mathrm{m}^{2}$ based on field sampling, and 5,288,304 $\mathrm{m}^{2}$ based on remote sensing 330 classification (5\% difference). Before comparing species estimates and associated error metrics, the 331 limitations of this analysis must be stated: (1) i-Tree canopy is multi-layered, therefore the canopy 332 totaled across all species includes understory trees. The remote sensing estimate is single-layered, 333 meaning that the sum of all canopy cover equals the citywide total canopy cover. That said, the median 334 crown light exposure for the 612 i-Tree trees was 4 (meaning 4 out of 5 "sides" of the tree are exposed 335 to direct sunlight). We use this field measurement simply to demonstrate that understory trees are not

\footnotetext{
${ }^{1}$ Four of the 29 common species (Cinnamomum camphora, Eucalyptus ficifolia, Geijera parviflora, and Stenocarpus sinuatus) were considered "common" based on City of Santa Barbara data but were not recorded in any UFORE plots.
} 
prevalent. (2) The remote sensing estimates include uncommon species that were mapped as one of the common species. It is unknown whether the final remote sensing result over- or under- estimates the actual canopy of the common species.

The remote sensing estimates were checked for deviation from the i-Tree estimate (Table 2, col I) and also for area-weighted deviation based on the i-Tree canopy estimates (Table 2, col J). To allow for 341 this exercise, the i-Tree estimates were considered to be "ground truth". Quercus agrifolia i-Tree estimates and remote sensing outputs were within $3 \%$ of one another, and within $1 \%$ when weighted by area. Other common, large canopy species, such as Jacaranda mimosifolia and Pinus canariensis were quantified similarly with both methods. The largest area-weighted discrepancies were found for the palm, Syagarus romanzoffiana and Eucalyptus globulus.

The methods we used do not permit definitive assertions about which result is more accurate, due in part to inflated i-Tree Eco species $\sigma_{e}$ because of the low field plot count $(n=89)$. Nevertheless, some inferences can be made based on measures of uncertainty. For all but two feather palm species (Archontophoenix cunninghamia and Syagarus romanzoffiana) the remote sensing quantity disagreement (Table 2, col F) was less than the i-Tree $\sigma_{\mathrm{e}}$ (Table 2, col D), frequently by a substantial amount. The largest discrepancies in uncertainties are found in species that were infrequently sampled in our field plots (e.g., Platanus racemosa, Jacaranda mimosifolia, Magnolia grandiflora) but have generally large canopies, which both increases the i-Tree $\sigma_{\mathrm{e}}$ and facilitates accurate classification using hyperspectral imagery. For example, there was only one Platanus racemosa sampled in the field but its crown projection area at $450 \mathrm{~m}^{2}$ was more than twice as large as the next-largest species' average crown size. For a species like Magnolia grandiflora, remote sensing methods are likely more accurate because of the non-spatially random manner in which it is planted. Many of the city's Magnolia grandiflora's are planted as street trees on dedicated Magnolia street segments (Fig $\mathbf{3 b}$ ). This can lead to uneven presence-absence data from field sampling but adequate characterization from remote sensing due to large crowns and perhaps due to unique leaf properties. On the other hand, the small but common feather palms, Archontophoenix cunninghamia and Syagarus romanzoffiana are better estimated using field methods. This is especially true for Syagarus romanzoffiana because it was very common, relatively evenly distributed across land use classes, and is difficult to distinguish from Archontophoenix cunninghamia using remote sensing. 


\subsection{Leaf area index mapping}

Using the lidar-based allometric method, the average LAI of the entire study area was estimated to be 1.15 with LAI within canopy of 4.47 (Fig 4). This was $11 \%$ less than the field-based estimate of 1.29 (canopy LAI = 5.57). The model uncertainties associated with lidar-based and field-based estimates of LAl are unknown. However, Alonzo et al. (2015) showed that the crown-scale, lidar-derived LAI values closely matched effective LAI estimates made using laser penetration metrics, which are lidar proxies for gap fraction. That two methods relying on different theoretical underpinnings could produce similar results increases confidence that the final map has low model-driven error. The most likely source of error in the map is due to extrapolation of the regression models beyond the parameters of the field sampled data. The model was trained on a relatively small set of well-defined crowns but applied to automatically-delineated crown segments whose dimensions were frequently more varied and irregular. Measurement error was deemed negligible for both field estimates and lidar estimates. In the field, the mean absolute error of height measurements was estimated to be $<1 \mathrm{~m}$ through a series of remeasurements. For the lidar data on flat ground, the vertical measurement uncertainty was $0.02 \mathrm{~m}$ and Alonzo et al. (2015) showed a strong relationship between field-measured and lidar-measured tree crown length (height minus crown base height).

Leaf area index is the primary biophysical control on the magnitude of ecosystem services provided by trees in urban areas. However, the ultimate social value of benefits such as air pollution reduction, avoided stormwater runoff, and building energy-use modification are highly dependent on the location and context within the urban environment. With a mapped result we are able to report on, for example, LAI by land use (Fig 5) and LAI relative to climate-controlled structures (Fig 6 and Fig 4a). In the Santa Barbara study area, we used the "transportation" land-use class to represent roads and parking lots. The LAI of this class is 0.99 , which derives from a fractional cover of 0.22 and an average canopy LAI of 4.48 .

Canopy overhanging roads and parking lots is particularly relevant from both an air pollution reduction and stormwater runoff management perspectives (Nowak et al., 2014; Wang et al., 2008). Air pollution removal can be high along roadways due to high pollution, however it should also be noted that canopy can trap ground-level emissions thus producing a net increase in local concentrations (Gromke \& Ruck, 2009; Wania et al., 2012). Canopy located optimally near buildings can, through direct shading and evapotranspirative cooling, reduce energy use and consequently, $\mathrm{CO}_{2}$ emissions from power plants. In the summertime, to maximize the cooling benefits of trees, the preferred locations are the east, south, and west sides of buildings in order to shade structures (Simpson, 2002). In this study, 
we found that the most canopy was found to the northeast side of buildings (14.3\%), but very similar amounts were found to the NW, SW, and SE (Fig 6). It is likely that these directions are more heavily planted compared to the cardinal directions because of the predominant NW-SE layout of Santa Barbara's street grid. The latter set of results could be combined with lidar-extracted building information and perhaps utility data to more completely model the spatial variation in energy use throughout a city.

\subsection{Carbon storage mapping}

We developed two models for dry-weight carbon $(\mathrm{kg})$, one with separate equations for each leaf type and one for all leaf types pooled together. Using stepwise regression on all possible combinations of the 28 lidar structural measurements, the leaf type equations were as follows:

$\ln \left(\mathrm{C}_{\mathrm{b}}\right)=\ln \left(0.10+1.31 \mathrm{H}_{\mathrm{b}}+1.63 \mathrm{~W}_{\mathrm{b}}\right)$

$$
\ln \left(\mathrm{C}_{\mathrm{n}}\right)=\ln \left(-1.30+3.36 \mathrm{H}_{\mathrm{n}}-2.55 \mathrm{~W}_{\mathrm{n}}\right)
$$

$$
\ln \left(\mathrm{C}_{\mathrm{p}}\right)=\ln \left(-2.27+2.82 \mathrm{H}_{\mathrm{p}}-0.58 \mathrm{~W}_{\mathrm{p}}\right)
$$

The subscripts $b, n$, and $p$ denote broadleaf, needleleaf, and palm leaf types respectively. $H$ represents a height variable and $W$ represents a width variable (both in meters). Different specific height and width variables maximized the predictive power of the models for each leaf type. $H_{b}$ was the median height of lidar returns within a crown while $H_{n}$ and $H_{p}$ were both represented by the simple maximum tree height. $W_{b}$ was the width of the tree at mean canopy height, $W_{n}$ was the ratio of crown width to height at 75th percentile height, and $W_{p}$ was the ratio of crown height to width and the median height of the lidar returns within the crown. The pooled equation took the form of:

$$
\ln \left(\mathrm{C}_{\text {pool }}\right)=\ln \left(0.09+1.12 \mathrm{H}_{\text {pool }}+1.86 \mathrm{~W}_{\text {pool }}\right)
$$

where $H_{\text {pool }}$ and $W_{\text {pool }}$ were represented by the same height and width variables as the broadleaf model, thus, the two equations only differ in their coefficients.

In model formulation, the separated model yielded a better explanatory relationship between the lidar predictors and the $\mathrm{i}$-Tree response $\left(\mathrm{R}_{\text {sep }}^{2}=0.74, \mathrm{R}_{\text {pool }}^{2}=0.69\right)$ as well as lower mean absolute deviation in kilograms $\left(M A D_{\text {sep }}=30 \mathrm{~kg} \mathrm{C}, M A D_{\text {pool }}=60 \mathrm{~kg} \mathrm{C}\right)$. However, the $\mathrm{R}^{2}$ values became roughly equal when tested using holdout cross-validation. This suggests that the separated models were overfit, perhaps due to limited training data for palms and needleleaf species. Both models were then applied to all crown segments that intersected with one of the 89 i-Tree plots. Neither was clearly superior with respect to all of $R^{2}$, bias, MAD, and RMSE (Fig 7). The separated model resulted in a MAD (240 kg C) 
which was $18 \%$ lower than the pooled MAD (290 kg C) and a slope of 1.03 compared with a pooled model slope of 0.91 . However, the pooled model resulted in an RMSE (1020 kg C) which was $13 \%$ lower than the separated model RMSE $\left(1170 \mathrm{~kg} \mathrm{C}\right.$ ) and an $R^{2}$ of 0.75 compared to a separated model $R^{2}$ of 0.65. We believe these results suggest that the separated model was more accurate at more of the lower fractional cover plots, while the pooled model was more accurate at high cover, high biomass 433 plots.

The variables and coefficients selected for each leaf type model and the pooled model shed light on the difficulty of constructing a universal, urban-tree biomass equation. For example, palms and needleleaf trees were best characterized by simple maximum height measurements but broadleaf height was represented by the median height of lidar returns in the crown. This possibly indicates that variability in broadleaf crown biomass is related to variability in the internal density of leaves and branches. Also, bole dimensions (e.g., dbh) are important variables in estimating tree biomass and carbon. Previous studies have used a similar lidar metrics (e.g., height of median energy), to successfully estimate biomass in tropical (Drake et al., 2002) and temperate (Muss et al., 2011) forest settings. Palm trees, on the other hand, can be assumed more homogeneous in terms of their internal structure. It is also clear that palm biomass cannot be based strictly on height (e.g., consider the tall, spindly Washingtonia robusta). This is evidenced in the log-form equation by a complex compensation for height contribution to biomass by reduction in biomass with increased width and a negative intercept term.

The relative performance of the pooled and the separated models can also be examined vis-à-vis variables and coefficients. The variables in the pooled model were the same as those chosen for the broadleaf model confirming the dominance of broadleaf trees such as Quercus agrifolia and Platanus racemosa in the Southern California landscape. The coefficients differed mainly in that the pooled model placed greater emphasis on width $\left(\beta_{\text {pool }}=1.86, \beta_{b}=1.63\right)$ than height $\left(\beta_{\text {pool }}=1.12, \beta_{b}=1.31\right)$. This difference likely occurs because, at least, palm trees require a model emphasizing crown width. This difference likely results in the better performance of the pooled model on plots with very large broadleaf trees. The biomass of these trees (e.g., a $25 \mathrm{~m}$ wide Platanus racemosa) was underestimated using the broadleaf model that was more driven by height. This example highlights a situation where a pixel-based biomass estimate may prove superior to a crown-based estimate. Raciti et al. (2014) successfully estimated carbon storage in Boston, Massachusetts' broadleaf-dominated urban forest using only lidar data gridded into a canopy height model. Nevertheless, there is clear degradation of the pooled model performance on plots with palm and needleleaf trees. This is most evident on plots with tall, 
Washingtonia robusta, whose biomass is vastly overestimated by the pooled model. Given the goal of creating a carbon storage map that maximizes accuracy at the most locations (rather than total carbon storage for the city), all further analysis was conducted using the model separated by leaf type.

The total amount of carbon stored in the study area's trees is 50,991 metric tons ( $t$ ), based on aggregated crown-scale lidar estimates. The modeled carbon storage based on field sampling was $55,900 \mathrm{t}$. The most carbon per unit area and per unit canopy area was stored in Natural-AgriculturalRecreation land uses (Fig $\mathbf{8 b}$ ). This pattern was expected because these areas are less developed and have coherent stands of large-canopy native species such as Quercus agrifolia and Platanus racemosa (Fig 8a). The least carbon per unit area was found in the industrial zone due to a combination of low stem counts and preferential planting of small canopy trees. However, in industrial zones the amount of carbon per unit canopy area remained high. This may be driven by high modeled carbon density for palm trees which are more prevalent in these zones.

Citywide, the lidar estimate equates to a carbon storage density of $22.4 \mathrm{t} \mathrm{C} \mathrm{ha}^{-1}$. This value is below the national average urban value of $25.1 \mathrm{t} \mathrm{C} \mathrm{ha}^{-1}$ reported in Nowak and Crane (2002), as would be expected given Santa Barbara's semi-arid climate. In our study area, the single family residential landuse class had a carbon storage density of $24.9 \mathrm{t} \mathrm{C} \mathrm{ha}^{-1}$ aligning it more closely with the national estimate. However, this residential estimate is well below the $32.8 \mathrm{t} \mathrm{C} \mathrm{ha}^{-1}$ estimate for residential land use in the naturally-forested setting of Boston (Raciti et al., 2014). Hutyra et al. (2011) estimated terrestrial carbon stocks along an urban to rural gradient in Seattle, Washington, creating a map of biomass based on a regional land cover map and mean biomass values for the grouped cover classes of heavy, medium, and low urban, and mixed and coniferous forest. They noted a clear trend of increased biomass per hectare with decreased urbanization intensity. We obtained similar results albeit at finer spatial resolution and thematic specificity: Carbon storage is lowest in industrial areas, and increases through commercial, multi-family residential, single family residential, to a high value in Natural-Agricultural-Recreation land uses (Fig 8b).

The above results are largely a function of simple variation in canopy cover and are not good indicators of carbon density per unit canopy area. When translated to this carbon density metric, Hutyra et al. (2011), for example, found $3.3,7.1$, and $11.6 \mathrm{~kg} \mathrm{C} \mathrm{m}^{-2}$ tree canopy on high, medium, and low intensity urban land uses respectively. Nowak et al. (2013) aggregated carbon density rates from throughout the United States finding a mean of $7.69 \mathrm{~kg} \mathrm{C} \mathrm{m}^{-2}$ and a range of 3.14 to $14.1 \mathrm{~kg} \mathrm{C} \mathrm{m}^{-2}$. They note that there is less variability among cities in this metric than a C-per-unit-land-area metric that is 
heavily influenced by fractional cover. In the downtown Santa Barbara study area the mean carbon density was $8.94 \mathrm{~kg} \mathrm{C} \mathrm{m}^{-2}$, ranging narrowly from single family residential on the low end $\left(7.88 \mathrm{~kg} \mathrm{C} \mathrm{m}^{-2}\right)$ to Natural-Agricultural-Recreation on the high end (11.0 $\mathrm{kg} \mathrm{C} \mathrm{m}^{-2}$, Fig $\left.8 \mathbf{b}\right)$.

The citywide standard error of the plot-based estimate was 9,899 $\mathrm{t}$ (17.7\%). This value represented sampling error only and did not account for the uncertainty of the biomass equations. The uncertainty associated with applying various biomass equations has been shown to have a variability up to 60 percent for population estimates (McHale et al., 2009). The lidar estimates have no sampling error but they do internalize the uncertainties of the i-Tree model related to application of biomass equations (i.e., the lidar models assume no error in the carbon estimates from i-Tree).

Additional uncertainty was introduced to the lidar estimates through generation of leaf-type models using linear regression. First, misclassification of crowns to the leaf-type level led to selection of the incorrect allometric equation. For example, the carbon storage of one correctly segmented juniper that was misclassified as a broadleaf was estimated by $\mathrm{i}$-Tree to be $180 \mathrm{~kg}$ but only $20 \mathrm{~kg}$ in the lidar model. Second, generalization to the leaf-type level reduced sensitivity to species-level biomass variation. The carbon storage of the most prevalent species, Quercus agrifolia was consistently underestimated by the lidar model because the leaf type equation was trained on many broadleaf species whose crown heights and widths related to lower biomass. Nevertheless, it was shown above that the pooled model was likely adequate for large-scale estimation of biomass, especially in areas with high broadleaf fractional cover. This result opens the door for future accounting of urban biomass even where hyperspectral data for leaf type classification are not available.

\section{Summary and Conclusions}

Remote sensing methods can provide detailed information about the spatial variation in urban

514 forest structure and function across the city. The resultant maps enhance our ability to understand 515 spatially varying ecological, public health, social, economic, and management processes. The primary goal of this research was to estimate urban forest structure and function at the individual tree crown

517 scale for every tree in an urban area using airborne remote sensing. It should be noted that the 518 assemblage of waveform lidar data and hyperspectral imagery used in this project is not yet commonly 519 available to cities. However, similar measurements can be taken in the near term using lidar data (which 520 is becoming quite common in cities) fused with high resolution multispectral imagery such as 521 WorldView-3. WV-3 is one of a new generation of sensors that is equipped with a red edge band and 522 several bands in the shortwave infrared range shown to be valuable for species discrimination (Alonzo et 
al., 2014). This fusion would facilitate mapping at least to the leaf-type level as well as robust estimation of LAl and carbon storage.

Building on the results of Alonzo et al. (2014), we created a species map that included every tree in our $22 \mathrm{~km}^{2}$ downtown Santa Barbara study area. Sampling error was eliminated from this product and 527 the quantity disagreement born of classification error was substantially less than the standard error 528 from plot-based estimates. Moreover, we showed that the spatial patterns of native species found in 529 natural stands and introduced species planted in highly managed areas could be well represented. Visualization of these species distribution patterns at fine spatial resolution will be of immediate use to managers seeking to prepare for pests, target invasive species, or maximize their urban forest's ecosystem services (Alberti, 1999, 2005; Manning, 2008).

Second, we mapped leaf area index for each tree in the study area using lidar measurements of crowns and an allometric approach, following the methods in Alonzo et al. (2015). The uncertainty of the lidar-based estimate for each plot was considered to be on par with the field-based approach based on good alignment with both field-based results and results using a lidar proxy for gap fraction inversion. Again, sampling error is not present in the final, citywide map. We believe that, in the future, this spatial product will allow for refined modeling of stormwater runoff reduction and building energy-use modification. Further, spatially explicit LAI can facilitate mapping of air pollution reduction benefits at a very fine resolution compared to what has previously been available. Future research incorporating distributed measurements of pollution emissions could additionally enhance the utility of these maps.

Finally, we mapped urban tree carbon storage using lidar measurements of crown structure such as height and width, with allometric models. Results from lidar models separated by leaf type corresponded well to field-based estimates on the more urban plots (i.e., low fractional cover, low biomass) while results from the pooled model proved superior for plots in naturally-occurring, high biomass stands. While our remote sensing based maps do not have the sampling error of a field inventory, they do have uncertainties stemming from the application of the biomass equations used in iTree, remote sensing classification to the leaf type level, and extrapolation of the stepwise regression model beyond the values encountered in the field-measured training data. Still, the final, spatially explicit product offers finer grain insight into the capacity for urban areas to store carbon and how urbanization patterns mediate this process.

This research demonstrates the capability for wall-to-wall, spatial estimation of the urban forest structure and function using airborne remote sensing. Maps of urban forest structure extend plot sampling results significantly by allowing for (1) measurement of difficult-to-access areas (e.g., private 
property, steep slopes); (2) analysis of the spatial relationships between tree canopy and other spatial urban variables such as population, economic activity, or health; (3) more frequent repetition of measurement and finer-grain (spatial and temporal) capacity for change detection; and (4) data consistency that is minimally dependent on field personnel. While there will always be a need for fieldbased urban ecosystem analysis, remote sensing data products greatly increase the breadth of scientific questions that can be asked as well as the specificity, reliability, and extensiveness with which those questions might be answered.

\section{Acknowledgments}

This research was funded by the first author's EPA-STAR Fellowship (FP-91768801-0), the National Science Foundation (BCS-0948914), and the Garden Club of America Fellowship in Urban Forestry. Special thanks to Robert Hoehn, Alexis Ellis, and Satoshi Hirabayashi for their work customizing, running, and communicating i-Tree Eco sub-models.

\section{References}

Alonzo, M., Bookhagen, B., Mcfadden, J. P., Sun, A., \& Roberts, D. A. (2015). Mapping urban forest leaf area index with airborne lidar using penetration metrics and allometry. Remote Sensing of Environment, 162, 141-153.

Alonzo, M., Bookhagen, B., \& Roberts, D. A. (2014). Urban tree species mapping using hyperspectral and lidar data fusion. Remote Sensing of Environment, 148, 70-83.

Alonzo, M., Roth, K. L., \& Roberts, D. A. (2013). Identifying Santa Barbara's urban tree species from AVIRIS imagery using canonical discriminant analysis. Remote Sensing Letters, 4(5), 513-521.

Chen, J. M., \& Black, T. (1992). Defining leaf area index for non-flat leaves. Plant, Cell \& Environment, 15, 421-429.

Churkina, G., Brown, D.G., Keoleian, G. (2010) Carbon stored in human settlements: the conterminous United States. Global Change Biology, 16, 135-143.

Congalton, R. G. (1991). A Review of Assessing the Accuracy of Classifications of Remotely Sensed Data. Remote Sensing of Environment, 37, 35-46.

Drake, J. B., Dubayah, R. O., Clark, D. B., Knox, R. G., Blair, J. B., Hofton, M. a., ... Prince, S. (2002). Estimation of tropical forest structural characteristics, using large-footprint lidar. Remote Sensing of Environment, 79(2-3), 305-319. 
Escobedo, F. J., \& Nowak, D. J. (2009). Spatial heterogeneity and air pollution removal by an urban forest. Landscape and Urban Planning, 90(3-4), 102-110.

Ferraz, A., Bretar, F., Jacquemoud, S., Gonçalves, G., Pereira, L., Tomé, M., \& Soares, P. (2012). 3-D mapping of a multi-layered Mediterranean forest using ALS data. Remote Sensing of Environment, $121,210-223$.

Green, R. O., Eastwood, M. L., Sarture, C., Chrien, T. G., Aronsson, M., Chippendale, B., ... Williams, O. (1998). Imaging spectroscopy and the airborne visible/infrared imaging spectrometer (AVIRIS). Remote Sensing of Environment, 65(3), 227-248.

Herold, M., Roberts, D. A., Gardner, M. E., \& Dennison, P. E. (2004). Spectrometry for urban area remote sensing -- Development and analysis of a spectral library from 350 to $2400 \mathrm{~nm}$. Remote Sensing of Environment, 91, 304-319.

Heynen, N., Perkins, H., \& Roy, P. (2006). The Political Ecology of Uneven Urban Green Space: The Impact of Political Economy on Race and Ethnicity in Producing Environmental Inequality in Milwaukee. Urban Affairs Review, 42(1), 3-25.

Hirabayashi, S., Kroll, C. N., \& Nowak, D. J. (2011). Component-based development and sensitivity analyses of an air pollutant dry deposition model. Environmental Modelling \& Software, 26(6), 804-816.

Hutyra, L. R., Yoon, B., \& Alberti, M. (2011). Terrestrial carbon stocks across a gradient of urbanization: a study of the Seattle, WA region. Global Change Biology, 17(2), 783-797.

Jensen, J., \& Cowen, D. (1999). Remote sensing of urban suburban infrastructure and socio-economic attributes. Photogrammetric Engineering and Remote Sensing, 65(5), 611-622.

Kokaly, R. F., Asner, G. P., Ollinger, S. V, Martin, M. E., \& Wessman, C. A. (2009). Remote Sensing of Environment Characterizing canopy biochemistry from imaging spectroscopy and its application to ecosystem studies. Remote Sensing of Environment, 113, S78-S91.

Kuo, F. E., \& Sullivan, W. C. (2001). Environment and Crime in the Inner City: Does Vegetation Reduce Crime? Environment and Behavior, 33(3), 343-367.

Laćan, I., \& McBride, J. R. (2008). Pest Vulnerability Matrix (PVM): A graphic model for assessing the interaction between tree species diversity and urban forest susceptibility to insects and diseases. Urban Forestry \& Urban Greening, 7(4), 291-300.

MacFaden, S. W., O'Neil-Dunne, J., Royar, A. R., Lu, J. W. T., \& Rundle, A. G. (2012). High-resolution tree canopy mapping for New York City using LIDAR and object-based image analysis. Journal of Applied Remote Sensing, 6(1), 063567-1.

Manning, W. J. (2008). Plants in urban ecosystems: Essential role of urban forests in urban metabolism and succession toward sustainability. The International Journal of Sustainable Development and World Ecology, 15(4), 362-370. 
621

622

623

624

625

626

627

628

629

630

631

632

633

634

635

636

637

638

639

640

641

642

643

644

645

646

647

648

649

650

651

652

653

McCarthy, H. R., \& Pataki, D. E. (2010). Drivers of variability in water use of native and non-native urban trees in the greater Los Angeles area. Urban Ecosystems, 13(4), 393-414.

McHale, M. R., Burke, I. C., Lefsky, M., Peper, P. J., \& McPherson, E. G. (2009). Urban forest biomass estimates: is it important to use allometric relationships developed specifically for urban trees? Urban Ecosystems, 12(1), 95-113.

McPherson, E. G., Simpson, J. R., Xiao, Q., \& Wu, C. (2011). Million trees Los Angeles canopy cover and benefit assessment. Landscape and Urban Planning, 99(1), 40-50.

Muss, J. D., Mladenoff, D. J., \& Townsend, P. a. (2011). A pseudo-waveform technique to assess forest structure using discrete lidar data. Remote Sensing of Environment, 115(3), 824-835.

Nowak, D. J. (1996). Estimating Leaf Area and Leaf Biomass of Open-Grown Deciduous Urban Trees. Forest Science, 42(4).

Nowak, D. J. (2012). Contrasting natural regeneration and tree planting in fourteen North American cities. Urban Forestry and Urban Greening, 11(4), 374-382.

Nowak, D. J., \& Crane, D. E. (2002). Carbon storage and sequestration by urban trees in the USA. Environmental Pollution, 116(3), 381-389.

Nowak, D. J., Crane, D. E., Stevens, J., Hoehn, R. E., Walton, J., \& Bond, J. (2008a). A ground-based method of assessing urban forest structure and ecosystem services. Arboriculture and Urban Forestry, 34(6), 347-358.

Nowak, D. J., Hoehn, R. E., Bodine, A. R., Greenfield, E. J., \& O’Neil-Dunne, J. (2013). Urban forest structure, ecosystem services and change in Syracuse, NY. Urban Ecosystems.

Nowak, D. J., Hoehn, R. E., Crane, D. E., Clarke, L. W., \& Davila, A. (2010). Assessing Urban Forest Effects and Values: Los Angeles' Urban Forest. Resource Bulletin NRS-47, USDA Forest Service.

Nowak, D. J., Hoehn, R. E., Crane, D. E., Stevens, J. C., \& Walton, J. T. (2006). Assessing Urban Forest Effects and Values: Washington, D.C.'s Urban Forest. Resource Bulletin NRS-1, USDA Forest Service.

Nowak, D. J., Walton, J., Stevens, J., Crane, D. E., \& Hoehn, R. E. (2008b). Effect of plot and sample size on timing and precision of urban forest assessments. Arboriculture and Urban Forestry, 34(6), 386390.

Peters, E. B., \& McFadden, J. P. (2010). Influence of seasonality and vegetation type on suburban microclimates. Urban Ecosystems, 13(4), 443-460.

Pillsbury, N. H., Reimer, J. L., \& Thompson, R. (1998). Tree volume equations for fifteen urban species in California. Urban Forest Ecosystems Institute, California Polytechnic State University.

Popescu, S. C. (2007). Estimating biomass of individual pine trees using airborne lidar. Biomass and Bioenergy, 31(9), 646-655. 
654

655

656

657

658

659

660

661

662

663

664

665

666

667

668

669

670

671

672

673

674

675

676

677

678

679

680

681

682

683

684

685

Raciti, S. M., Hutyra, L. R., \& Newell, J. D. (2014). Mapping carbon storage in urban trees with multisource remote sensing data: Relationships between biomass, land use, and demographics in Boston neighborhoods. Science of The Total Environment, 500-501, 72-83.

Richardson, J. J., \& Moskal, L. M. (2014). Uncertainty in urban forest canopy assessment : Lessons from Seattle, WA, USA. Urban Forestry \& Urban Greening, 13, 152-157.

Richter, R., \& Schlaepfer, D. (2002). Geo-atmospheric processing of airborne imaging spectrometry data. Part 2: atmospheric/topographic correction. International Journal of Remote Sensing, 23(13), 3741.

Roberts, D. A., Ustin, S. L., Ogunjemiyo, S., Greenberg, J., Dobrowski, S. Z., Chen, J. M., \& Hinckley, T. M. (2004). Spectral and Structural Measures of Northwest Forest Vegetation at Leaf to Landscape Scales. Ecosystems, 7(5), 545-562.

Santamour, F. S. (1990). Trees for urban planting: Diversity, uniformity, and common sense. In Proceedings of the Seventh Conference of the Metropolitan Tree Improvement Alliance (METRIA) (pp. 57-65).

Schwarz, K., Fragkias, M., Boone, C. G., Zhou, W., McHale, M., Grove, J. M., ... Cadenasso, M. L. (2015). Trees Grow on Money: Urban Tree Canopy Cover and Environmental Justice. Plos One, 10(4), e0122051.

Simpson, J. (2002). Improved estimates of tree-shade effects on residential energy use. Energy and Buildings, 34(10), 1067-1076.

Sprugel, D. G. (1983). Correcting for bias in log-transformed allometric equations. Ecology.

Urban, J. (1992). Bringing order to the technical dysfunction within the urban forest. Journal of Arboriculture, 18(2), 85-90.

Ustin, S. L., Gitelson, A. A., Jacquemoud, S., Schaepman, M., Asner, G. P., Gamon, J. a., \& Zarco-Tejada, P. (2009). Retrieval of foliar information about plant pigment systems from high resolution spectroscopy. Remote Sensing of Environment, 113, S67-S77.

Welch, R. (1982). Spatial resolution requirements for urban studies. International Journal of Remote Sensing, 3(2), 1982.

White, R. H., \& Zipperer, W. C. (2010). Testing and classification of individual plants for fire behaviour: plant selection for the wildland-urban interface. International Journal of Wildland Fire, 19(2), 213.

Woodcock, C., \& Strahler, a. (1987). The factor of scale in remote sensing. Remote Sensing of Environment, 21(3), 311-332.

Xiao, Q., \& McPherson, E. G. (2002). Rainfall interception by Santa Monica's municipal urban forest. Urban Ecosystems, 6, 291-302. 
687 Xiao, Q., Ustin, S. L., \& McPherson, E. G. (2004). Using AVIRIS data and multiple-masking techniques to 688 map urban forest tree species. International Journal of Remote Sensing, 25(24), 5637-5654.

689 Zhang, C., \& Qiu, F. (2012). Mapping Individual Tree Species in an Urban Forest Using Airborne Lidar 690 Data and Hyperspectral Imagery. Photogrammetric Engineering \& Remote Sensing, 78(10), 1079$691 \quad 1087$. 
Figures for the submission: Mapping urban forest structure and function using hyperspectral imagery and lidar data

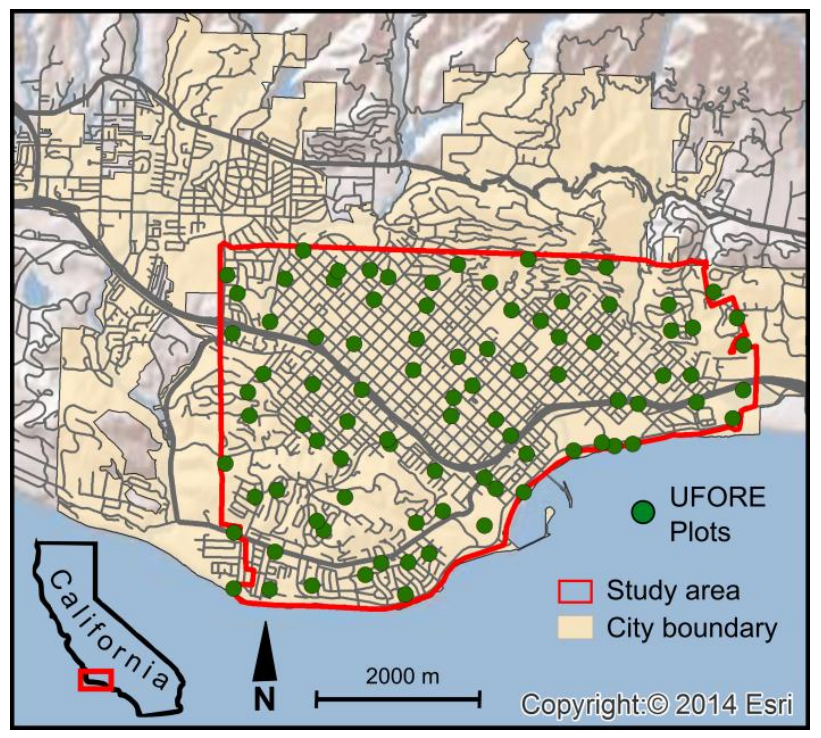

Figure 1: Study area $\left(22.7 \mathrm{~km}^{2}\right)$ with 89 i-Tree Eco plots. 

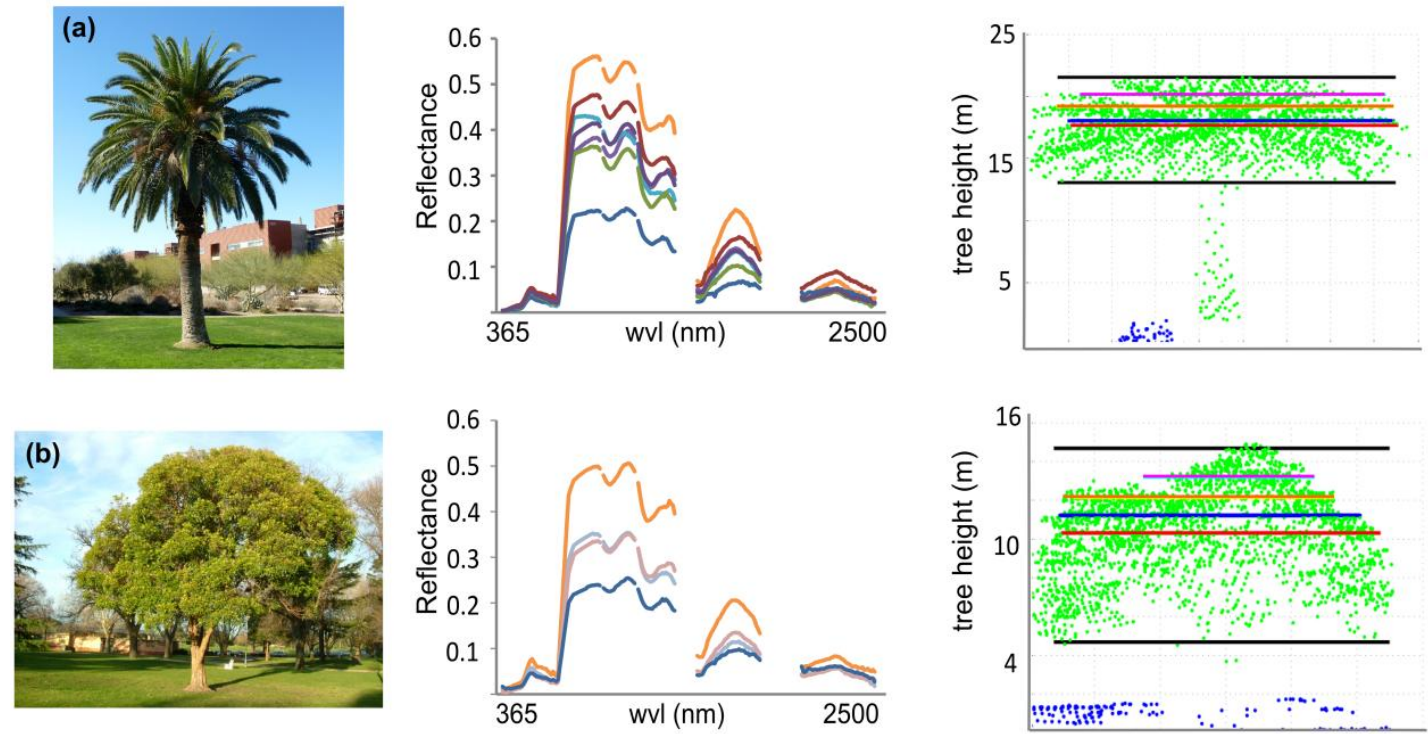

Figure 2: (a) Phoenix canariensis photo, AVIRIS spectra extracted from one crown, and set of crown-level structural measurements. Black lines indicate crown base and max heights. Red line is mean crown height. Dark blue is median height of returns in crown. Orange and violet show $75^{\text {th }}$ and $90^{\text {th }}$ percentile heights as well as widths at those heights. (b) Same set of information but for the broadleaf evergreen, Lophostemon confertus. 


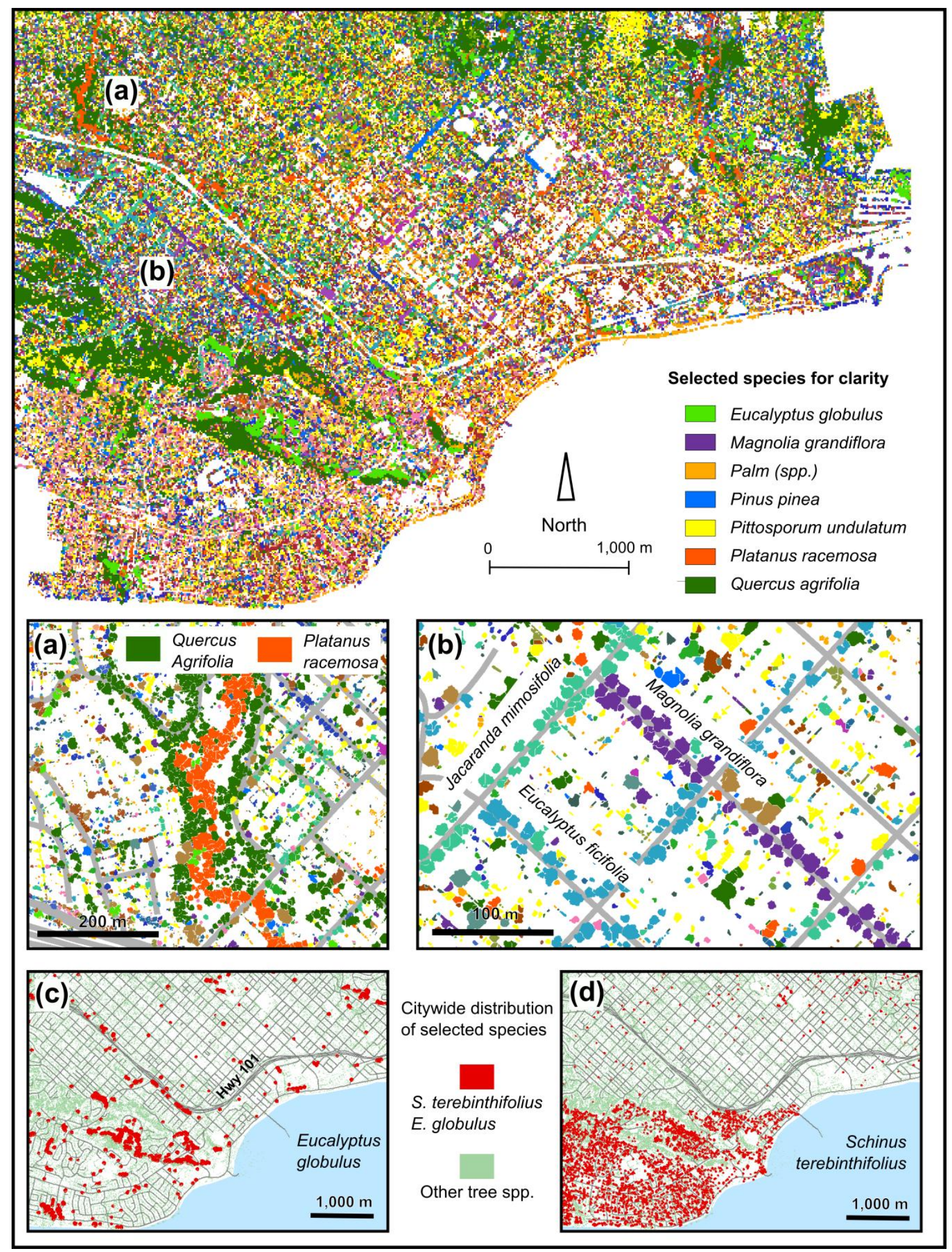

Figure 3: Species maps. The main map shows the species with the most canopy in each $10 \mathrm{~m}$ grid square. (A) Riparian corridor; (B) Linear street tree planting; (C) Distribution of E. Globulus; (D) Distribution of $S$. terebinthifolius that is partly an artifact of illumination and sensor geometry. 


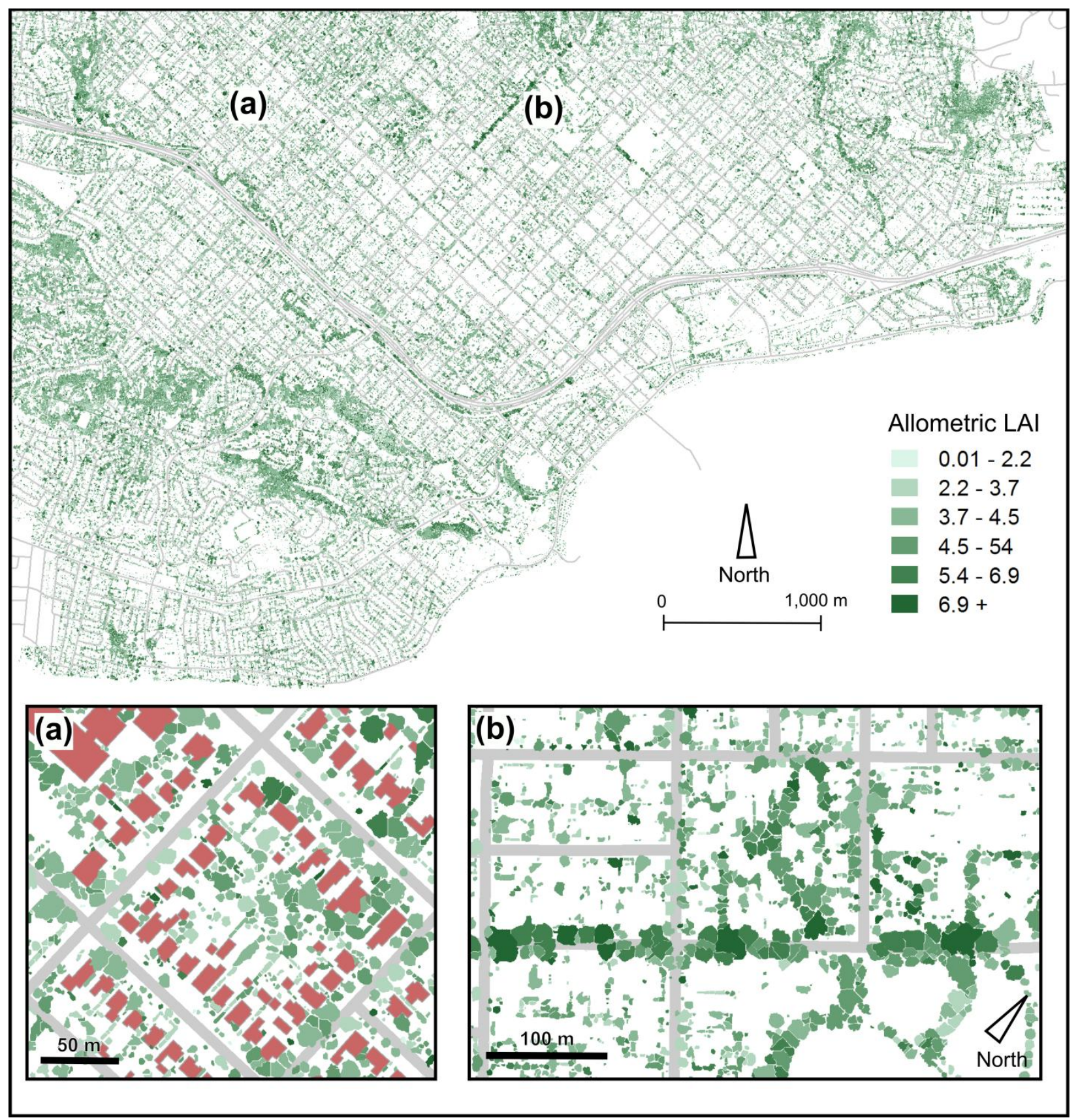

Figure 4: The main map shows LAI calculated using allometric methods at the crown scale. (A) Example of fine scale spatial relationship between buildings and canopy. (B) Example of canopy overhanging impervious surface. 


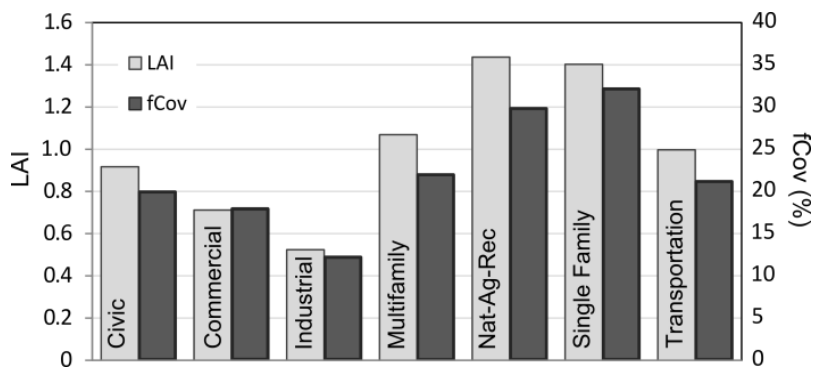

Figure 5: Leaf area index (LAI) and canopy fractional cover by land use 


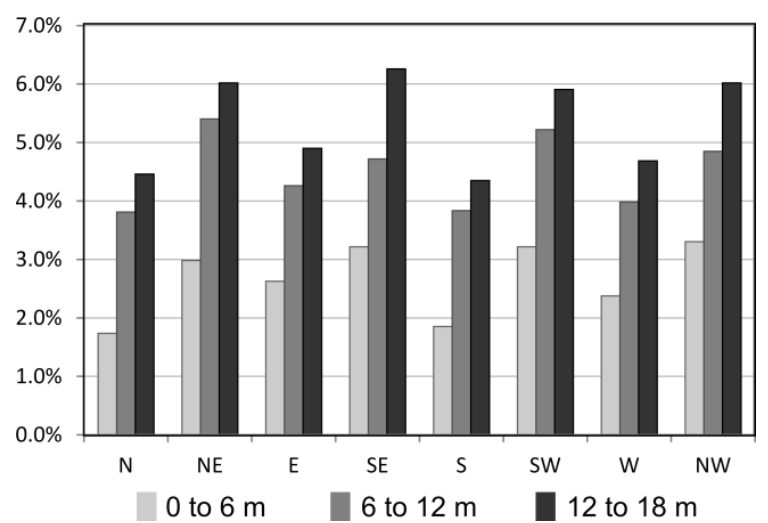

Figure 6: Average distance and direction of canopy from buildings as a percentage of all canopy within $18 \mathrm{~m}$ of buildings (Simpson et al. 2002). 
(a) Separate models by leaf type

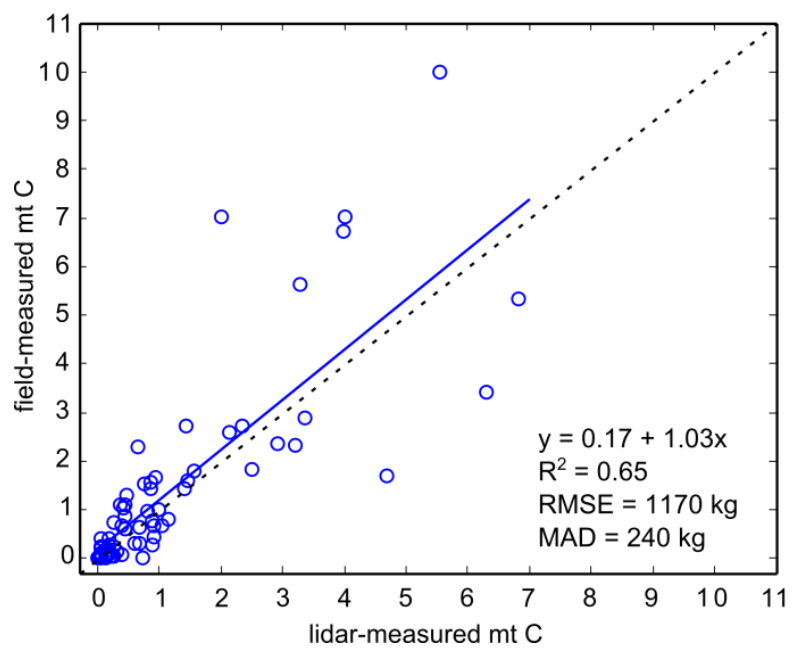

(b) Pooled model

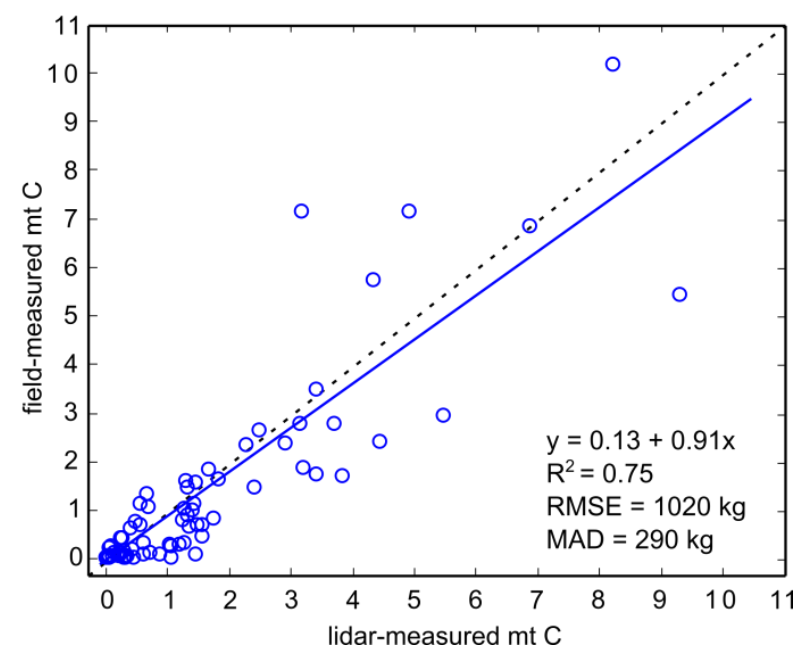

Figure 7: Predicting field-measured dry-weight carbon using lidar. (a) The plot-level result using one allometric equation for each leaf type (broadleaf, needleleaf, palm). (b) The same but with only one allometric equation for all trees. Dashed line is $1: 1$ and blue line is best linear fit. 


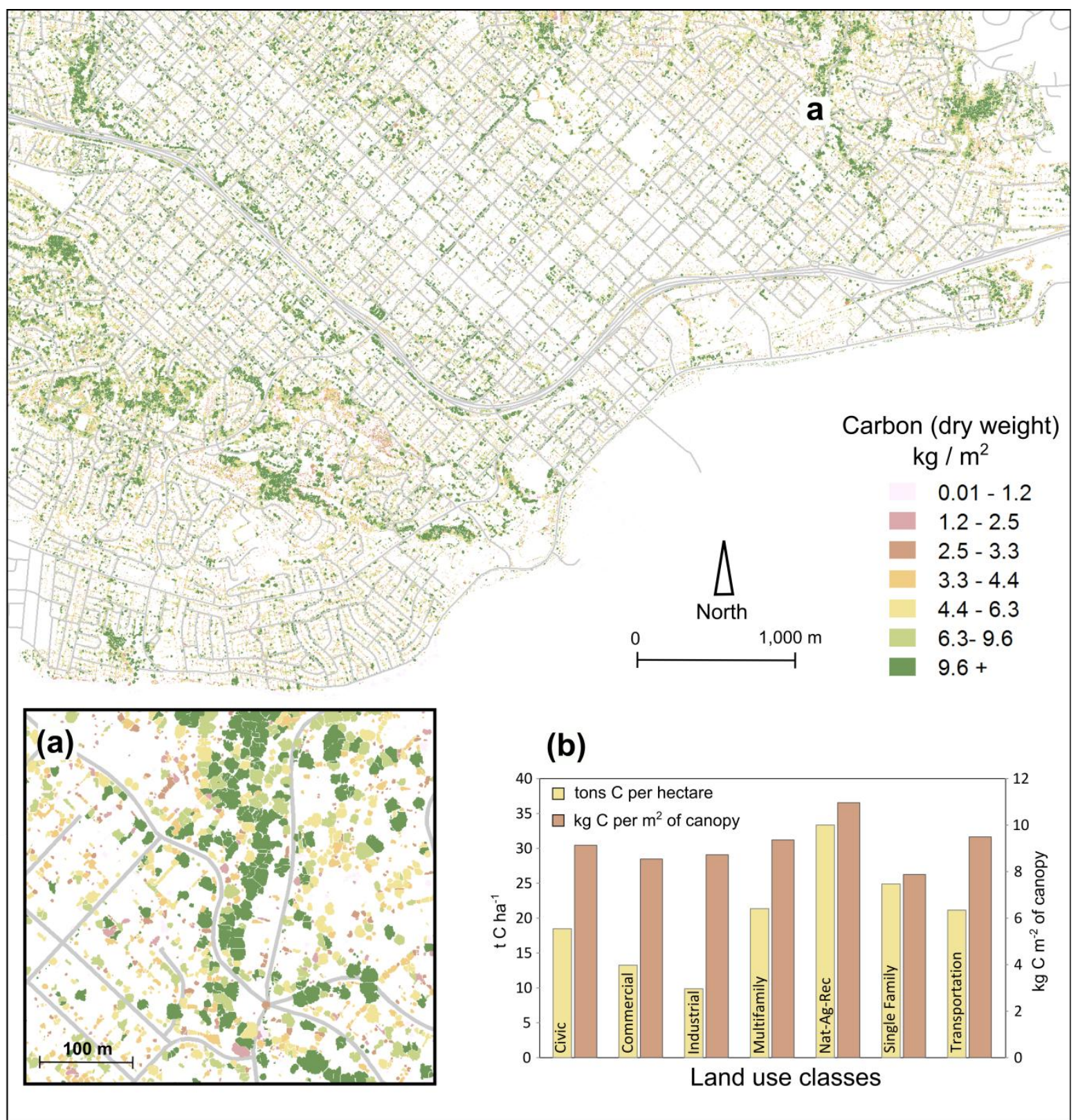

Figure 8: Main map shows dry-weight carbon per $\mathrm{m}^{2}$ at the crown scale. (a) Zoom in on riparian corridor. (b) Carbon by land use. 
This document contains the table captions and images of the tables showing how we intended for them to appear in print (roughly). The editable tables will be uploaded separately. Not that table 2 contains and important footnote.

Table 1: Land use classes used in this study along with land use representativeness of field plots.

\begin{tabular}{lccc}
\hline LU class & Study area $\left(\mathrm{km}^{2}\right)$ & Study area (\% total) & Plot area (\%) \\
\hline Civic & 1.50 & 6.6 & 9.7 \\
Commercial & 1.64 & 7.3 & 7.5 \\
Industrial & 0.86 & 3.8 & 6.4 \\
Multifamily & 3.10 & 13.7 & 9.4 \\
Nat-Ag-Rec & 2.40 & 10.6 & 12.1 \\
Single Family & 8.02 & 35.5 & 29.2 \\
Transportation & 5.05 & 22.4 & 25.7 \\
\hline
\end{tabular}


Table 2: Comparison of $\mathrm{i}$-Tree and remotely sensed citywide estimates of species composition including indicators of uncertainty. Column $\mathrm{K}$ is weighted by the i-Tree-estimated canopy area. Remote sensing metrics (Quantity disagreement, Producer's/User accuracy) are based on a validation sample of 2,304 crowns. $^{1}$

\begin{tabular}{|c|c|c|c|c|c|c|c|c|c|}
\hline A & B & C & D & E & $\mathbf{F}$ & G & H & $\mathbf{I}$ & J \\
\hline $\begin{array}{l}\text { Common Species } \\
\text { Botanical name }\end{array}$ & $\begin{array}{l}\text { Leaf } \\
\text { Type }\end{array}$ & $\begin{array}{c}\text { Eco } \\
\text { Canopy Area } \\
\text { (sq m) }\end{array}$ & $\begin{array}{c}\text { Eco } \\
\text { Std. Err. } \\
\text { (89 plots) }\end{array}$ & $\begin{array}{c}\text { Rem. Sens. } \\
\text { Canopy Area } \\
\text { (sq m) }\end{array}$ & $\begin{array}{c}\text { Rem.Sens. } \\
\text { Quantity } \\
\text { Disagreement }\end{array}$ & $\begin{array}{c}\text { Rem. Sens. } \\
\text { Producer's } \\
\text { Accuracy }\end{array}$ & $\begin{array}{c}\text { Rem. Sens. } \\
\text { User } \\
\text { Accuracy }\end{array}$ & $\begin{array}{c}\text { Eco } \\
\text { Rem. Sens. } \\
\text { Difference }\end{array}$ & $\begin{array}{c}\text { Eco / RS } \\
\text { Area Weig. } \\
\text { Difference }\end{array}$ \\
\hline Archontoph. cunningham. & $\mathrm{P}$ & 56,476 & $80 \%$ & 140,148 & $85 \%$ & $65 \%$ & $35 \%$ & $148 \%$ & $1 \%$ \\
\hline Cupressus macrocarpa & C & 240,367 & $83 \%$ & 201,714 & $-1 \%$ & $90 \%$ & $91 \%$ & $-16 \%$ & $-1 \%$ \\
\hline Eucalyptus globulus & B & 507,152 & $66 \%$ & 224,757 & $-5 \%$ & $93 \%$ & $98 \%$ & $-56 \%$ & $-5 \%$ \\
\hline Ficus microcarpa & B & 28,262 & $99 \%$ & 57,771 & $-8 \%$ & $92 \%$ & $100 \%$ & $104 \%$ & $1 \%$ \\
\hline Jacaranda mimosifolia & B & 207,450 & $70 \%$ & 215,859 & $-1 \%$ & $95 \%$ & $95 \%$ & $4 \%$ & $0 \%$ \\
\hline Liquidambar styraciflua & B & 96,553 & $72 \%$ & 160,027 & $-7 \%$ & $87 \%$ & $93 \%$ & $66 \%$ & $1 \%$ \\
\hline Lophestemon confertus & B & 62,006 & $88 \%$ & 70,072 & $-19 \%$ & $61 \%$ & $75 \%$ & $13 \%$ & $0 \%$ \\
\hline Magnolia grandiflora & B & 38,706 & $73 \%$ & 148,203 & $7 \%$ & $92 \%$ & $86 \%$ & $283 \%$ & $2 \%$ \\
\hline Metrosideros excelsa & B & 88,613 & $80 \%$ & 230,892 & $-9 \%$ & $42 \%$ & $46 \%$ & $161 \%$ & $3 \%$ \\
\hline Olea europaea & B & 205,110 & $51 \%$ & 105,296 & $-12 \%$ & $83 \%$ & $94 \%$ & $-49 \%$ & $-2 \%$ \\
\hline Phoenix canariensis & $P$ & 42,534 & $99 \%$ & 68,888 & $-24 \%$ & $64 \%$ & $84 \%$ & $62 \%$ & $0 \%$ \\
\hline Pinus canariensis & C & 233,419 & $68 \%$ & 262,396 & $47 \%$ & $85 \%$ & $58 \%$ & $12 \%$ & $1 \%$ \\
\hline Pinus pinea & C & 251,804 & $89 \%$ & 183,910 & $9 \%$ & $97 \%$ & $89 \%$ & $-27 \%$ & $-1 \%$ \\
\hline Pittosporum undulatum & B & 539,596 & $40 \%$ & 628,007 & $-24 \%$ & $72 \%$ & $95 \%$ & $16 \%$ & $2 \%$ \\
\hline Platanus racemosa & B & 290,274 & $99 \%$ & 239,742 & $-14 \%$ & $83 \%$ & $97 \%$ & $-17 \%$ & $-1 \%$ \\
\hline Podocarpus gracilior & B & 57,421 & $95 \%$ & 123,380 & $7 \%$ & $92 \%$ & $86 \%$ & $115 \%$ & $1 \%$ \\
\hline Pyrus kawakamii & B & 155,534 & $54 \%$ & 173,642 & $31 \%$ & $76 \%$ & $58 \%$ & $12 \%$ & $0 \%$ \\
\hline Quercus agrifolia & B & $1,394,467$ & $35 \%$ & $1,353,001$ & $15 \%$ & $89 \%$ & $77 \%$ & $-3 \%$ & $-1 \%$ \\
\hline Schinus molle & B & 17,203 & $99 \%$ & 44,545 & $-25 \%$ & $32 \%$ & $43 \%$ & $159 \%$ & $0 \%$ \\
\hline Schinus terebinthifolius & B & 232,994 & $70 \%$ & 176,253 & $-1 \%$ & $93 \%$ & $94 \%$ & $-24 \%$ & $-1 \%$ \\
\hline Syzygium australe & B & 126,894 & $39 \%$ & 76,132 & $9 \%$ & $87 \%$ & $80 \%$ & $-40 \%$ & $-1 \%$ \\
\hline Syagarus romanzoffiana & $\mathrm{P}$ & 458,426 & $39 \%$ & 49,241 & $-55 \%$ & $36 \%$ & $80 \%$ & $-89 \%$ & $-7 \%$ \\
\hline Tipuana tipu & B & 118,399 & $89 \%$ & 156,739 & $14 \%$ & $99 \%$ & $87 \%$ & $32 \%$ & $1 \%$ \\
\hline Ulmus parvifolia & B & 20,795 & $99 \%$ & 150,966 & $-18 \%$ & $69 \%$ & $84 \%$ & $626 \%$ & $2 \%$ \\
\hline Washingtonia robusta & $\mathrm{P}$ & 114,134 & $46 \%$ & 46,724 & $-14 \%$ & $66 \%$ & $76 \%$ & $-59 \%$ & $-1 \%$ \\
\hline
\end{tabular}

\footnotetext{
${ }^{1}$ Quantity disagreement is the difference between the amount of canopy classified as a certain species and the actual amount of that species' canopy; location agreement is not considered. Producer's accuracy quantifies classification accuracy (quantity and location) in terms of error of omission. User accuracy is the same as Producer's but for errors of commission.
} 
Table 3: Secondary accuracy assessment for ten most important species in terms of canopy area using City of Santa Barbara street trees as validation dataset. Instead of User accuracy we show the extent to which uncommon species were mapped as one of these common species. For example, $40 \%$ of trees that were labeled on the map as $C$. macrocarpa were actually an uncommon species. The uncommon species that was most frequently labeled as $C$. macrocarpa was $M$. quinquinervia. The former is needleleaf while the latter is broadleaf so leaf type agreement, in this case, was not achieved.

\begin{tabular}{lcclc}
\hline $\begin{array}{l}\text { Common species } \\
\text { botanical name }\end{array}$ & $\begin{array}{l}\text { Producers } \\
\text { accuracy }\end{array}$ & $\begin{array}{l}\text { Mapped } \\
\text { uncommon }\end{array}$ & $\begin{array}{l}\text { Most frequently mapped } \\
\text { uncommon species }\end{array}$ & $\begin{array}{l}\text { Leaf type } \\
\text { agreement? }\end{array}$ \\
\hline Cupressus macrocarpa & $98 \%$ & $40 \%$ & Melaleuca quinquinervia & No \\
Eucalyptus globulus & $98 \%$ & $42 \%$ & Eucalyptus cornuta & Yes \\
Jacaranda mimosifolia & $87 \%$ & $10 \%$ & Maytenus boaria & Yes \\
Pinus canariensis & $57 \%$ & $33 \%$ & Pinus torreyana & Yes \\
Pinus pinea & $97 \%$ & $19 \%$ & Pinus halepensis & Yes \\
Pittosporum undulatum & $47 \%$ & $34 \%$ & Brachychiton discolor & Yes \\
Platanus racemosa & $82 \%$ & $32 \%$ & Koelreuteria bipinnata & Yes \\
Quercus agrifolia & $76 \%$ & $20 \%$ & Quercus ilex & Yes \\
Schinus terebinthifolius & $83 \%$ & $33 \%$ & Cupaniopsis anacardioides & Yes \\
Syagrus romanzoffianum & $26 \%$ & $13 \%$ & Trachycarpus fortunei & Yes \\
& & & & \\
\hline
\end{tabular}

